\title{
The Effects of Input Factors on the Growth of the Agricultural Economy Empirical Study of Syria
}

\author{
Fadi Alammar \\ South China Agricultural University, Guangzhou, China
}

\begin{abstract}
This paper analyzes the effect of input factors on the growth of the agricultural sector in Syria. It estimates the relationship between input factors and agricultural economic growth in Syria using cointegration analysis and Granger causality analysis. The results of the analysis show that: (1) The increase of agriculture labor force and financial support played a vital role in the agricultural economic growth in the long term; (2) The increase in agricultural land and capital investment is significant in promoting agricultural economic growth in the short term; (3) Agricultural capital investment and agriculture labor force are the Granger causes of the agricultural economic growth.
\end{abstract}

Keywords: agricultural economic growth, input factors, Syria

\section{Introduction}

The agricultural sector plays an important role in the overall economy of Syria. A large number of the population is directly engaged in agriculture or agriculture-related enterprises. In fact from previous studies, the population involved in agriculture accounted for about $51 \%$ of the total population. More so, the agricultural sector output contributes about 30\% of the total GDP. Agricultural labor employment is also about $30 \%$ of the employed labor force. From 1999-2002, the Syrian agricultural exports accounted for about 14\% of total exports, but this data has continued to fluctuate in recent years. Cotton is the main cash crop in Syria. Other cash crops include cereals, vegetables, fruits, and tobacco (World Bank, 2005b; FAO, 2005; Encyclopedia of the Nations, 2005).

However, the development of agriculture in overall economic development is not prominent. According to Anda and Mohamed (2010), average expenditure growth in the rural regions varied between $-0.84 \%$ in the north-eastern rural region to $3.4 \%$ in the middle rural region, while average expenditure growth in the urban regions varied from 2.5 in the coastal urban region to $4.7 \%$ in the middle urban region. Agriculture is the main income source to about $56 \%$ of the total rural population (El-Ghonemy, 2005). However, the level of agricultural production in Syria is also relatively low and inefficient. Only about 30\% of Syria's total land area is cultivated and only less than $10 \%$ is irrigated. Consequently, agricultural production is mainly dependent on rainfall, which has hindered further development of the agricultural production due to the irregular pattern. More so, the heavy drought in the late 1990 and 2008 has had serious impacts on agricultural production in Syria.

According to El-Ghonemy (2005), three elements in the reform of agricultural policies may contribute to

Fadi Alammar, Ph.D. in Agricultural Economics and Management, College of Economics and Management, South China Agricultural University.

Correspondence concerning this article should be addressed to Fadi Alammar. E-mail: fadialammar@hotmail.com. 
explain the observed evolution in the rural areas. Firstly, the sale of some large public farms to private landowners who switched to more capital-intensive production techniques; Secondly, the freezing of the land reform which was the main characteristic of the Syrian agricultural policies in the previous decades; Thirdly, the reduction of the state intervention in inputs distribution and products marketing (except for strategic crops). For this, the Syrian government adopted a series of policy measures to promote agriculture and economic growth. The general Syrian sustainable agriculture development aims at: securing food self-sufficiency, increasing exports, improving living standard of rural population, curtailing rural migration and supplying necessary raw materials for agro-industries.

In order to tackle the impact of financial crisis in Syria's economic growth and to ensure steady economic growth and development, the government began a series of adjustments on the economic and fiscal policies with the aim of stimulating economic growth. In the field of agriculture, the policy options include: strengthening economic exchanges with developed countries and developing countries, attracting more international economic assistance; in order to achieve the objective of the Eleventh Five-Year Plan, increasing support efforts to agricultural development, provision of 246 billion Syrian pounds financial support to agriculture within the next four years, increasing an additional 10 million jobs (currently 948,000) in the field of agriculture and irrigation and finally steady provision of feed and fertilizer financial subsidies.

The total state budget expenditures of 2009 financial year were 685 billion Syrian pounds. The total expenditure compared with the previous fiscal year increased by 85 billion Syrian pounds, an increase of 14.17\%. This $14.17 \%$ increment in the total expenditure will be used to subsidize the basic agricultural production, fertilizer, feed prices, the construction of agricultural infrastructure such as irrigation and export subsidies.

Clearly, whether agricultural growth can be sustainably achieved or not, will have a direct bearing on Syria future economic growth trend. Therefore, in the context of this macro-strategy, this study re-examines and evaluates the economic input factors in agriculture since reform and quantitatively analyzes the performance of various agricultural production inputs factors in the process of agricultural economic growth and then provides the feasible proposal of Syrian agricultural economic growth. This is very significant and will help address the various practical and theoretical issues.

There are three lines of enquiry. First is the test for cointegration between input factors (including agriculture capital investment, agricultural labor, land and agricultural financial support) and agricultural economic growth in Syria; The second will be the use of Granger causality analysis to test the causality relationship between input factors and agricultural economic growth. The paper is organized as follows: Section 2 reviews some literature on the input factors-agricultural economic growth relationship, section 3 will discuss the empirical methods for the study, while section 4 will analyze the data and presents the results. Finally, section 5 will provide policy recommendations, summary and conclusion.

\section{Empirical Method, Data and Results}

\section{Testing for Unit Roots}

We often assume that time series data used is stationary when conducting time-series econometric analysis, but actually a lot of time series data, especially the time series data about macro-economy are non-stationary. Stationarity of time series data is the basic requirement in the econometric statistics, and is one of the 
prerequisites which ensure the correctness of measurement results. Non-stationary time series data may lead to "spurious regression" problem, as follows: There is actually no causal relationship between the two original variables, but it does have a high correlation. The existence of this situation makes the conclusions inferred from the use of traditional methods encounter great problems. In the past 20 years, with advances in time series analysis, judgments and processing of the non-stationary series data have had a great improvement. Among them includes judgment of test for stationary time series, stationary unit root test, and the co-integration test, Granger causality test, all of which are gradually developed analytical methods about time series test handling in this period. The Augmented Dickey-Fuller (ADF) test will be mainly used in this research.

\section{Data and Variables}

In the analysis of the input elements in the agricultural contribution to economic growth, the data for this research is obtained from the Annual Agricultural Statistical Abstract. All price-related variables have been adjusted in price index of 2000, interval of the sample is the year of 1985-2009, in which the variables as follows.

Dependent variable. The agricultural output is the dependent variable. Agricultural output data is from Syrian Bureau of Statistics National Accounts, total agricultural output $(Y)$ was calculated at 2,000 constant prices in the total value of agricultural and forestry replaced (unit: Syrian million pounds).

\section{Independent variables.}

(1) Capital investment in agriculture: the stock of fixed assets to agriculture;

(2) Agricultural labor input: estimates of labor employed in agriculture are difficult in Syria for lack of appropriate consistent data. This data comes from the Annual Agricultural Statistical Abstract, and the labor is over 17 years old;

(3) Land: use of indicators of the total sown area of crops, and the land sown area is measured in hectares;

(4) Financial support of agriculture: Syria fiscal flows to agriculture.

Table 1

Descriptive Statistics of the Natural Logarithm of Variables During 1985-2009

\begin{tabular}{lccccc}
\hline & $\mathrm{Y}$ & $\mathrm{K}$ & $\mathrm{L}$ & $\mathrm{N}$ & \multicolumn{2}{l}{$\mathrm{F}$} \\
\hline Mean & 12.53667 & 11.43638 & 13.83720 & 8.448716 & 8.433948 \\
Median & 12.63388 & 11.53279 & 13.81034 & 8.459352 & 8.435549 \\
Maximum & 12.97783 & 11.85122 & 14.18911 & 8.606302 & 8.758412 \\
Minimum & 11.91448 & 10.63506 & 13.26975 & 8.240121 & 8.010692 \\
Std. Dev. & 0.331063 & 0.341048 & 0.263442 & 0.085545 & 0.199026 \\
Skewness & -0.501846 & -0.976629 & -0.239084 & -0.679821 & -0.333017 \\
Kurtosis & 1.900389 & 2.838184 & 2.106895 & 3.710621 & 2.206299 \\
Jarque-Bera & 2.308896 & 4.001462 & 1.069042 & 0.293512 & 1.118294 \\
Probability & 0.315231 & 0.135236 & 0.585950 & 2.451676 & 0.571696 \\
Sum & 313.4169 & 285.9095 & 345.9301 & 211.2179 & 210.8487 \\
Sum Sq. Dev. & 2.630461 & 2.791533 & 1.665643 & 0.175632 & 0.950673 \\
\hline
\end{tabular}

Note. Source: The Annual Agricultural Statistical Abstract (1985-2009).

The selected variables were all in the process of natural logarithm, and such process can not only keep the useful information of the variables based on economic theory, but also eliminate collinearity, heteroscedasticity 
effects. Variables of agricultural capital, agricultural labor, land, financial support of agricultural after taking the natural logarithm are respectively reprepresented by $\ln y, \ln x$, in which: $Y$ is the natural logarithm of agricultural output; $K$ is the natural logarithm of agricultural capital investment; $L$ is the natural logarithm of the agricultural labors; $N$ is the natural logarithm of effective sown area of crops; $F$ is the natural logarithm of financial support of agricultural. $b 1, b 2, b 3, b 4$ are respectively the elasticity coefficient of $K, L, N$ and $F$. Descriptive statistics of time series of the natural logarithm of variables is shown in Table 1.

\section{Unit Root Tests}

According to ADF test process, this paper makes unit root test on the five time series $Y, K, L, N, F$. The test results found that under all three cases, the five variables of the original time series cannot reject the null hypothesis that are non-stationary series, so proceeding to the five time series of the first order differential ADF test, the result shows that the five differential variables reject the unit root null hypothesis in the intercept and constant model respectively at significant levels of $5 \%, 1 \%, 5 \%, 1 \%, 1 \%$, the test result is shown in Table 2, from the result we can say that first-order difference time series of $Y, K, L, N, F$ are stationary.

Table 2

$Y, K, L, N$, F First Difference of the ADF Test Results

\begin{tabular}{llllll}
\hline Variable names & ADF $t$ value & $1 \%$ critical value & $5 \%$ critical value & $10 \%$ critical value & Prob. $^{*}$ \\
\hline$\Delta Y$ & $-3.990^{* *}$ & -4.468 & -3.645 & -3.261 & 0.026 \\
$\Delta K$ & $-7.067^{* * *}$ & -4.416 & -3.662 & -3.249 & 0.000 \\
$\Delta L$ & $-4.316^{* *}$ & -4.416 & -3.622 & -3.249 & 0.012 \\
$\Delta N$ & $-5.231^{* * *}$ & -4.498 & -3.658 & -3.269 & 0.002 \\
$\Delta F$ & $-11.034^{* * *}$ & -4.416 & -3.622 & -3.249 & 0.000
\end{tabular}

Notes. In the Augment Dickey and Fuller (ADF), "," ", , 'reject the null hypothesis, respectively, $1 \%, 5 \%, 10 \%$ of the level of statistical significance. Source: The Annual Agricultural Statistical Abstract (1985-2009); Syrian Bureau of Statistics National Accounts.

\section{Cointegration Test}

In order to use Johansen cointegration analysis to examine the existence of cointegration relationship of the variables, the first step is to determine the lag order of VAR model. However, there is a contradiction in the process: In practice, if the lag order is large enough, it can completely reflect the dynamic characteristics of structural models. However, the model has the less freedom if the lag order is long enough. The longer the lag orders is, the less freedom the model has. Therefore, there should be a balance between the lag order and the degree of freedom. Generally, we use the minimum values of AIC and SC criteria to determine the lag order. According to the criteria above, the optimal model is the VAR (3) model (AIC $=-19.606$, SC $=-15.638$ ). The choice of optimal lag is shown in Table 3.

The second step is the cointegration tests, and the cointegration test is actually an unconstrained VAR model. The unit root test results suggest that the first difference time series of $Y, K, L, N, F$ are stationary, so that there may exist cointegration between them. Using Johansen maximum likelihood test for cointegration test, the results show that (see Table 4) between $Y$ and $K, L, N$, F, there may exist cointegration relationship, that is to say that there is a long-term equilibrium relationship among these variables, so they can build the regression equation. 
Table 3

VAR Vector Auto-regression Optimal Choice of Time Lag

\begin{tabular}{lllllll}
\hline Lag & LogL & LR & FPE & AIC & SC & HQ \\
\hline 0 & 104.040 & NA & $8.46 \mathrm{e}-11$ & -9.004 & -8.756 & -8.945 \\
1 & 179.399 & 109.612 & $9.33 \mathrm{e}-13$ & -13.582 & -12.094 & -13.231 \\
2 & 206.694 & 27.295 & $1.16 \mathrm{e}-12$ & -13.790 & -11.063 & -13.148 \\
3 & 295.662 & $48.528^{*}$ & $1.49 \mathrm{e}-14^{*}$ & $-19.606^{*}$ & $-15.638^{*}$ & $-18.671^{*}$ \\
\hline
\end{tabular}

Notes. Indicates lag order selected by the criterion; LR: sequential modified LR test statistic (each test at 5\% level); FPE: Final prediction error; AIC: Akaike information criterion; SC: Schwarz information criterion; HQ: Hannan-Quinn information criterion. ${ }^{*}$ reject the null hypothesis $10 \%$ of the level of statistical significance. Source: The Annual Agricultural Statistical Abstract (1985-2009); Syrian Bureau of Statistics National Accounts.

Table 4

Johansen Cointegration Test

\begin{tabular}{lllll}
\hline Variables & Lag order & Trace statistic & Critical value (5\%) & No. of cointegration relations \\
\hline (Y, K) & 3 & 44.843 & 25.872 & None $^{*}$ \\
& & 16.074 & 12.517 & At most one $^{* *}$ \\
$(\mathrm{Y}, \mathrm{L})$ & 3 & 16.505 & 15.495 & None $^{* *}$ \\
& 3.030 & 3.841 & At most one $^{* *}$ \\
$(\mathrm{Y}, \mathrm{N})$ & 3 & 55.997 & 25.872 & None $^{* *}$ \\
& \multirow{3}{*}{3} & 15.086 & 12.518 & At most one $^{* *}$ \\
$(\mathrm{Y}, \mathrm{F})$ & 3 & 11.545 & 5.495 & None $^{* *}$ \\
& & 4.925 & 3.841 & At most one $^{* * *}$
\end{tabular}

Note. ${ }^{* *},{ }^{*}$ reject the null hypothesis, respectively, 5\%, 10\% of the level of statistical significance. Source: The Annual Agricultural Statistical Abstract (1985-2009); Syrian Bureau of Statistics National Accounts.

Because the ADF test results show that in the intercept and a constant ADF model, the sequence of the first difference is stationary series, so on the base of stationary test, and cointegration test, the regression equation of $Y$, $K, L, N, F$ should include constant and trend, so the regression equation is as follows:

$$
\begin{aligned}
\mathrm{Y}= & 4.3081+0.0194 \mathrm{~T}+0.1160 \mathrm{~K}+0.2075 \mathrm{~L}-0.2056 \mathrm{~N}+0.6540 \mathrm{~F} \\
& (3.527) \quad(4.426) \quad(0.8032) \quad(3.5057) \quad(-1.3367)
\end{aligned}
$$

where: $R$-squared 0.987630 , adjusted $R$-squared 0.984374 , S.E. of regression $0.041384, F$-statistic 303.3894 , Prob. (F-statistic) 0.000000.

From the regression results we can see, $R^{2}, F$-statistic are known, the equation is goodness of fit, the overall significant is good. The results of unit root test of residual ECM suggest that ECM term is less than $10 \%$ statistical confidence level of the critical value, so we can say that ECM is smooth, there is a long-term stable relationship between the capital, labor, land, financial support of agriculture and economic growth in agriculture. In this equilibrium relationship, the capital output elasticity is 0.12 , indicating that capital investment increased by 1 to promote agricultural growth of $12 \%$ increase; labor output elasticity is 0.21 , indicating that the labor input increased by 1 to promote agricultural economic growth of 21\% increase; land of output elasticity is -0.21 , indicating that the land increase did not promote the growth of the agricultural economy in the years 1985-2009. It implies that in this period an effective increase in land increased by 1 will hinder $21 \%$ agricultural economic growth; financial support of agriculture elasticity is 0.65 , indicating an increase of 1 per financial support of 
agricultural will promote agricultural economic growth by $65 \%$. But it should be noted, from the regression equation, the regression coefficients of $K, N$ did not pass the $t$-test, which means that the impact of $K, N$ on agricultural economic growth are not statistically significant in the long term. Therefore, in the period 1985-2009, the impact of the increase of agricultural capital inputs and land to agricultural economic growth is not significant, while agricultural labor and financial support of agricultural in the long term appear to play a more significant role. Corresponding cointegration equation is as follows:

$$
\begin{aligned}
& \mathrm{Y}=\mathrm{E} \mathrm{C} \mathrm{M}+0.0194 \mathrm{~T}+0.1160 \mathrm{~K}+0.2075 \mathrm{~L}-0.2056 \mathrm{~N}+0.6540 \mathrm{~F}+4.3081 \\
& (9.42 \mathrm{E}+11)(9.56 \mathrm{E}+11) \quad(1.74 \mathrm{E}+11) \quad(7.57 \mathrm{E}+11)(-2.89 \mathrm{E}+11) \quad(1.10 \mathrm{E}+12)(7.62 \mathrm{E}+11)
\end{aligned}
$$

Among: $R$-squared 1.000000 , adjusted $R$-squared 1.000000, S.E. of regression 1.92E-13, $F$-statistic $1.20 \mathrm{E}+$ 25, Prob (F-statistic) 0.000000.

From $R^{2}, F$-statistic and $t$-statistic of equation (2), we can know, equation (2) is goodness of fit, the overall significance and the significant variables are good. From the estimated cointegration of equation (2), we can initially conclude that the input factors in the long term have different effects onS the Syrian agricultural economic growth. From a long-term view, to increase the agricultural labor input and financial support of agriculture will drive the growth of the agricultural economy, while increasing capital investment in agriculture and the land of agriculture to drive economic growth is not significant; in terms of promoting economic growth of agriculture, $F>L>0$, this shows that both financial support of agriculture and agricultural labor force can drive economic growth and keep the stability of agriculture, and their positive effects are relatively larger. Therefore, in the long term, financial support of agriculture and agricultural labor force are the two critical factors to promote agricultural growth.

According to the cointegration equation, we can get the following vector error correction model (VECM) (equation (3)) and the $t, p$ statistic values of VEC shown in Table 5:

$$
\begin{gathered}
\Delta \mathrm{Y}=1.7466 \mathrm{EC} \mathrm{M}+0.9304 \Delta \mathrm{Y}(-1)-0.7002 \Delta \mathrm{Y}(-2)+0.9453 \Delta \mathrm{K}(-1)+0.7573 \Delta \mathrm{K}(-2) \\
-0.1159 \Delta \mathrm{L}(-1)+0.2496 \Delta \mathrm{L}(-2)+0.3442 \Delta \mathrm{N}(-1)-0.9141 \Delta \mathrm{N}(-2)+0.2090 \Delta \mathrm{F}(-1)+0.5888 \Delta \mathrm{F}(-2)
\end{gathered}
$$

Among: $R$-squared 0.869828 , adjusted $R$-squared 0.751490 , S.E. of regression 0.053958 .

Table 5

The Statistics Data of VECM

\begin{tabular}{llcl}
\hline Variables & Std. error & $t$-value & $p$-value \\
\hline ECM & 0.43 & 4.04 & 0.00 \\
$\Delta Y(-1)$ & 0.46 & -2.03 & 0.07 \\
$\Delta Y(-2)$ & 0.38 & -1.85 & 0.09 \\
$\Delta K(-1)$ & 0.25 & 3.71 & 0.00 \\
$\Delta K(-2)$ & 0.18 & 4.20 & 0.00 \\
$\Delta L(-1)$ & 0.19 & -0.62 & 0.55 \\
$\Delta L(-2)$ & 0.19 & 1.32 & 0.21 \\
$\Delta N(-1)$ & 0.23 & 1.51 & 0.16 \\
$\Delta N(-2)$ & 0.33 & -2.80 & 0.02 \\
$\Delta F(-1)$ & 0.45 & 0.46 & 0.65 \\
$\Delta F(-2)$ & 0.39 & 1.53 & 0.16 \\
\hline
\end{tabular}

Note. Source: The Annual Agricultural Statistical Abstract (1985-2009); Syrian Bureau of Statistics National Accounts.

Cointegration relationship reflects the endogenous variables and the input time series variables are 
cointegrated relationship. Based on cointegration relations above, create the error correction model among $\Delta Y$, $\Delta K, \Delta L, \Delta N, \Delta F$, such as equation (3). ECM is the error correction term, reflecting the long-run equilibrium relationship between variables, the error correction term of ECM coefficients in VEC model reflects the size of the deviation from the adjustment of the long-run equilibrium. The coefficients of differential item of explanatory variables reflect the short-term fluctuations of explanatory variables impact the short-term change of independent variable. The ECM coefficients of $Y(-1), Y(-2)$ are negative, but the absolute values of coefficients are larger, negative correction is in line with the principle of VEC, also shows that lagged period of agricultural output plays an important role in agricultural output. The impact of early information of the agricultural output plays an important role in agricultural production, the smooth flow of information about supply and demand in agriculture should be given attention; the absolute value of ECM coefficient of input elements $K(-1), K(-2), N(-2)$ are larger and the $t$-statistics are significant, through these we can make the judgement that the capital investment of agriculture and agricultural land in the short term make a larger adjustment to the agricultural economic growth, but in the long term it is not obvious. In addition, the ECM coefficients of the input factors $L(-2), F(-1), F(-2)$ are larger and positive, but the $t$ value statistic are not significant, indicating that agricultural labor and the financial support of agriculture in the short term have some lag effect on economic growth of agriculture, but these effects are not significant in the short term, combined with the known equation cointegration we can infer that financial support of agriculture in the long run plays an more important impact on agricultural growth than in the short-term. So Syrian financial support of agriculture should attach more importance to the long-term sustainable financial input, and Syrian agricultural labor force quality is not high. In the short term, it can only depend on the increase of the quantities of the labor force to promote agricultural economic growth, but according to the empirical results, this extensive type of agricultural labor input did not generate significant economic growth, so the government should pay more attention to agricultural human capital investment and its long term role in promoting agricultural growth, the results are also in line with our previous cointegration equation results.

\section{Granger Causality Test}

Cointegration test results show that there is a stationary equilibrium relationship existing between the factor inputs and agricultural economic growth in the long-term in Syria, but further examination is still needed to inspect whether this balance constitutes a causal relationship. This paper uses methods proposed by Granger (1969) to analyze this issue. The results of Granger causality test are in Table 6.

Table 6

Granger Causality Test Table

\begin{tabular}{llll}
\hline Null hypothesis & Obs. & F-statistic & Probability \\
\hline$K$ does not granger cause $Y$ & \multirow{2}{*}{23} & 3.438 & 0.054 \\
$Y$ does not granger cause $K$ & & 0.511 & 0.608 \\
$L$ does not granger cause $Y$ & \multirow{2}{*}{23} & 2.636 & 0.099 \\
$Y$ does not granger cause $L$ & & 2.317 & 0.127 \\
$N$ does not granger cause $Y$ & \multirow{2}{*}{23} & 1.057 & 0.368 \\
$Y$ does not granger cause $N$ & & 0.737 & 0.493 \\
$F$ does not granger cause $Y$ & \multirow{2}{*}{23} & 2.031 & 0.160 \\
$Y$ does not granger cause $F$ & & 1.786 & 0.196 \\
\hline
\end{tabular}

Note. Source: The Annual Agricultural Statistical Abstract (1985-2009); Syrian Bureau of Statistics National Accounts. 
As can be seen from Table 6, the test results rejected the null hypothesis that $K$ is not a Granger cause of $Y$, but accepted the null hypothesis that $Y$ is not Granger cause of $K$, this result suggests that capital investment in agriculture is the Granger cause to agricultural economic growth, while agricultural economic growth promotes the capital investment in agriculture hasn't been supported by empirical evidence. These show that the agricultural capital inputs and agricultural economic growth in Syria is in a one-way causality. The test result supports the traditional agricultural theory of economic growth; $L$ is Granger cause of $Y$, and $Y$ is not Granger cause of $L$, which indicates that economic growth and labor in agriculture is the one-way Granger causality, the labor force promotes agricultural economic growth, and the reason leading to the contrary is not established; in the Granger causality test of $N$ and $Y, F$ and $Y$, the results fail to reject the null hypothesis, the empirical data show, land, financial support of agriculture that cause economic growth in agriculture have not obtained experience of support, the results are contrary to the cointegration analysis and the analysis of contradictions VEC that we have done. The explanation of this result is that this may be due to insufficient data, which leads to certain errors, and another is that this shows the financial support of agriculture to promoting the agricultural economy growth is not enough, so that the current financial support of agriculture to promote economic growth in agriculture has not emerged. From Figure 1 which is Syria's government financial support to agriculture it is in an increasing trend, but from Figure 2, it can be observed that the ratio of Syria financial support of agriculture to the total fiscal flows was in a decreasing trend, the value in 2009 is the lowest indicating that although there was an increasing trend of the state fiscal flows in absolute terms, but the country's agricultural policy has not really been inclined to the Syrian agricultural sector as an important sector for economic growth, decreasing financial support for agriculture also emphasizes the problem. Furthermore, with the fierce competition in international agriculture markets, Syrian agricultural extensive mode of economic growth cannot meet increasing competition of the international market. This implies that the corresponding agricultural promotion policies are needed to ensure the long-term sustainable development of agriculture in Syria.

SP Million

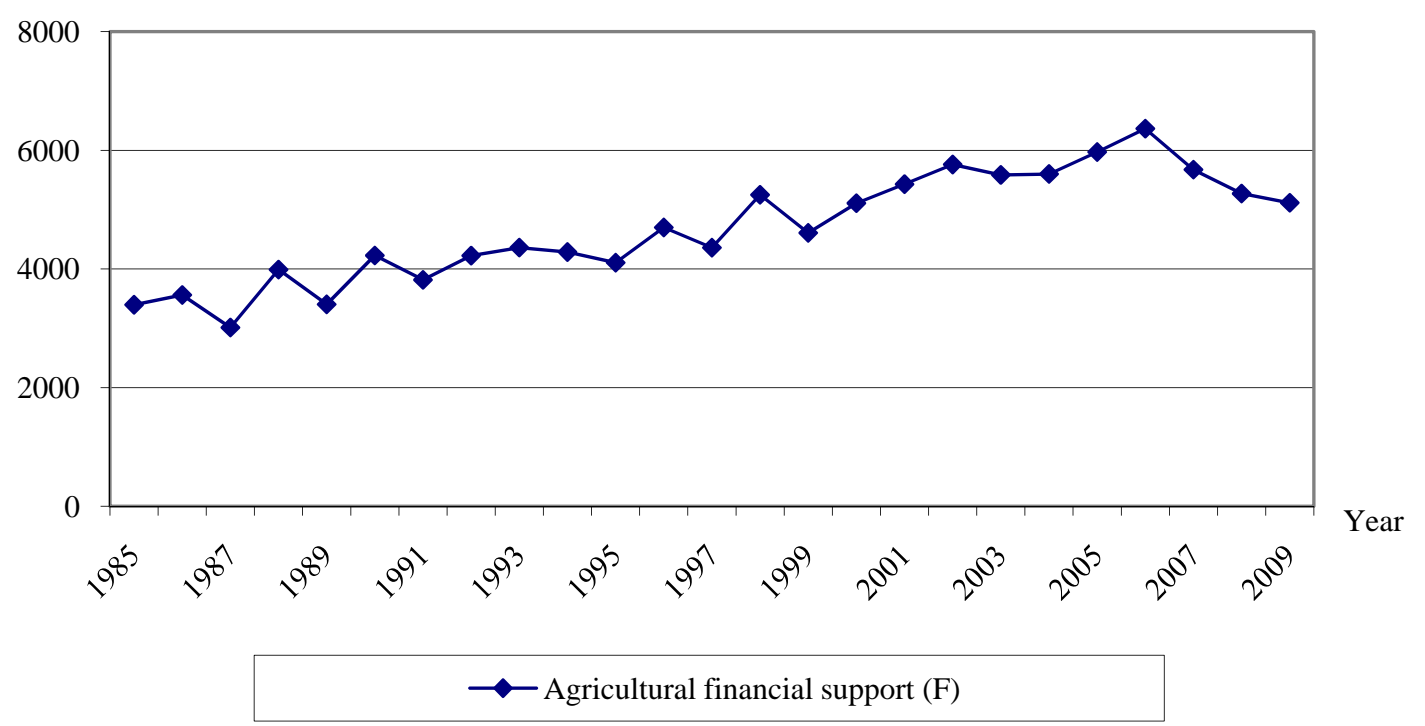

Figure 1. Syriafinancial support of agriculture of government 1985-2009. 


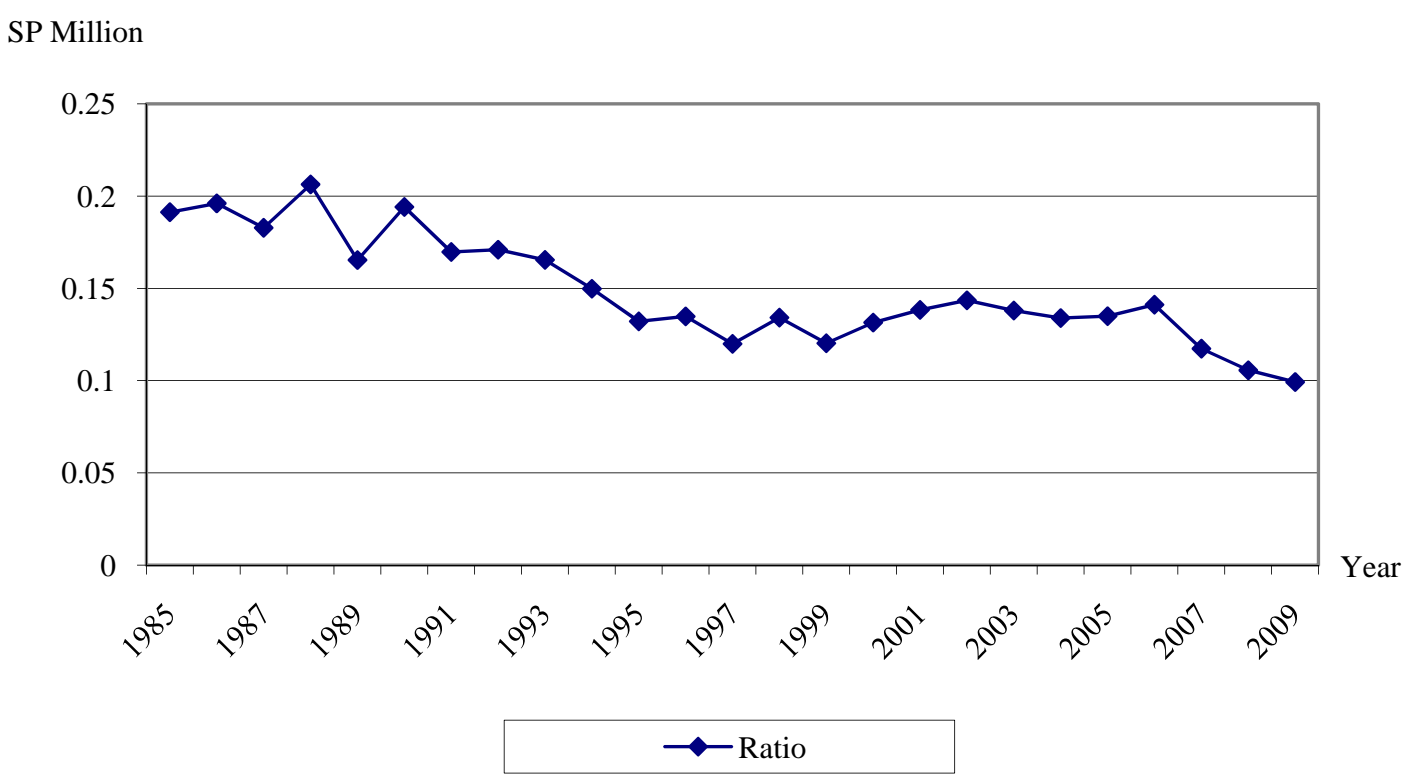

Figure 2. The proportion of Syria financial support of agriculture to the total fiscal flows 1985-2009.

\section{Conclusions}

In recent years, there have been a series of reforms in Syria's agricultural sector. Although it has achieved some remarkable results, it still is far from attaining efficient and sustainable levels. High population growth rates have caused a large number of rural people being unemployed and the unreasonable land allocation system makes the most of the agricultural resources concentrated on the hands of few large farmers. More so, the rate of concentrated agricultural capital is too high whereas agricultural productivity is low leading to a widening gap in rural wealth. Agricultural financial support is also relatively low. Rural infrastructure has seriously lagged behind agricultural development. Therefore, it is essential to research and explore the mechanism of the Syrian economic growth. This paper uses the growth of agricultural econometric data, related theoretical results, combined with the real situation of Syrian agriculture to analyze the agriculture inputs of agricultural economic growth, with the aim to find out the intersection of inspiration of the economics and management theory, econometrics and economic theory of agricultural technology. This research will not only fill the shortage in theory to some extent, but also contribute to deepening and development of the theory of agriculture economic growth, which will boost Syrian agricultural economic growth.

The results show that:

(1) In the long term, the increase of agriculture labor force and financial support plays the vital role in the agricultural economic growth. The two factors of agricultural labor and agricultural financial support are the two main drivers of agriculture economic growth, however there is no significance in the increase of agriculture land and capital investment on the role of promoting agricultural economic growth;

(2) In the short term, the role of the increase of agricultural land and capital investment in promoting agricultural economic growth is significant, whereas the role of the increase in agriculture labor input and financial support input has no significance;

(3) Agricultural capital investment and agriculture labor input are the Granger causes of the agricultural 
economic growth, the financial investment of land and agricultural is the reason for economic growth, but it has not been supported by experience.

However, this study is not without limitations. First, it is true that the factors affecting agricultural growth are many. As this paper use the economic measurement to analyze the impact factors of economic growth, so the model set that the data selection and the choice of estimation methods will inevitably affect the results. In this regard, this model remains to be further improved: A single equation model cannot explain the variable specificity effect on agricultural growth mechanisms, ways and degrees. Therefore, it is important that future researches should consider the introduction of simultaneous equations model, which makes the estimates with more policy implications. Secondly, section 2 analyzes the impact of capital investment in agriculture, agricultural labor, land, agricultural financial support impact to agricultural output from 1985 to 2009, and also makes a preliminary interpretation to the impact of different inputs factors to agriculture output. The work that remains for further studies includes: Firstly, the statistics of the agricultural capital, agricultural labor, and inputs of agricultural land need to be further adjusted. Currently, the estimate of agricultural capital and agricultural labor is still a shortage of uniform measurement method. Scholars often choose different calculation methods based on different purpose. In the future, it is necessary to further explore these elements into unified and reasonable measurement indicators. Also, the measurement data we used are mainly the time series data of agricultural output and the input factors. In the future, panel data should be considered to make comparative study on the input factors impact on agricultural output of the major regions in Syria. More so, the causes of regional differences should be analyzed and policy recommendations proffered for the government to improve the income gap.

\section{References}

Anda, M. D., \& Mohamed, A. M. (2010). Poverty reduction and growth interactions: What can be learned from the Syrian experience? Université Paris-Dauphine.

El-Ghonemy, R. (2005). Agriculture and rural poverty. Macroeconomic policies for poverty reduction: The case of Syria. UNDP report, Damascus, Syria, chapter 4, pp. 86-109.

Engle, R. F., \& Granger, C. W. J. (1987). Cointegration and error correction: Representation, estimation and testing. Econometrica, 55, 251-276.

Granger, C. W. J. (1969). Investigating the causal relations by econometric models and cross-spectral methods. Econometrica, 37(3), 424-438. 